\title{
CULTURE AFFECTS OUR BELIEFS ABOUT FIREARMS, BUT DATA ARE ALSO IMPORTANT
}

\author{
DAVID B. MUSTARD ${ }^{\dagger}$
}

\section{INTRODUCTION}

Dan Kahan and Donald Braman's provocative analysis contends that because people's beliefs about firearms are primarily formed by cultural values, empirical data are unlikely to have much effect on the gun debate. Their proposed solution to this quandary is that scholars who want to help resolve the gun controversy should identify precisely the cultural visions that generate this dispute and formulate appropriate strategies for enabling those visions to be reconciled in law.

In response to Kahan and Braman's challenge to empirical research, I argue that while culture influences beliefs, it is but one of several such factors. Alongside culture (and presumably other factors as well), empirical evidence has a powerful influence on beliefs about gun control. In the first Part of this Commentary I discuss how cultural beliefs can significantly affect individuals' beliefs about firearms and discuss strategies for helping people overcome their cultural biases to more honestly evaluate empirical evidence. The second Part provides examples of how data have played an important role in affecting individuals' beliefs about firearms. I conclude by urging renewed attention to empirical research to inform the gun control debate.

\section{The Role of Culture in Influencing Beliefs on GunS}

Are individuals' beliefs about firearms strongly influenced by culture? Do some citizens possess attitudes about firearms that will not be affected regardless of how much empirical evidence is set forth? Kahan and Braman's analysis suggests that the answer to both questions is "Yes." I agree that culture can play a very important role in

\footnotetext{
${ }^{\dagger}$ Assistant Professor of Economics, Terry College of Business, University of Georgia.

' Dan M. Kahan \& Donald Braman, More Sialistics, Less Persuasion: A Cullaral Theory of Gun-Risk Perceplions, 151 U. PA. L. REV. 1291, 1311-12 (2003) (arguing that "cul-
} 
defining people's beliefs about guns. In my writing and speaking about firearms I was shocked to learn how many people on both sides of the debate virtually ignore data that undermine their views. This cultural bias toward ignoring evidence could be extremely costly when formulating public policy on firearms because so many lives may be at stake as a result of the policy. I will draw from my experiences lecturing about gun control to illustrate how to simultaneously penetrate individuals' cultural biases and challenge them to more honestly consider evidence that may not be consistent with their cultural worldviews.

In my own lecturing on guns, I often ask people whether any data or evidence could lead them to change their minds on the issue of gun control. Often those who respond "no" are forced to reflect on their unwillingness to listen to evidence. To the extent that this response conflicts with their self-images as thoughtful persons, they are often willing to renew a discussion of the issue with an openness to the data. With those who respond to the question affirmatively, I follow up with another question: "What type of evidence would lead you to change your mind?" This often generates productive lines of inquiry into what it would really take for listeners to change their minds. Occasionally the evidence that they would require to change their minds already exists in empirical studies. At one such talk, a student said she was utterly repulsed by the idea of allowing law-abiding citizens to carry concealed weapons, because she thought this would lead to wholesale chaos and "wild west gunfights." When asked about the type of evidence she would need to change her mind, she indicated that she would need overwhelming evidence that people with concealed-carry permits used their firearms responsibly. I described to her some of the published studies about the low incidence of criminality among permit holders (parts of which I include in the next Part). After the talk she said that she intended to examine this issue more honestly to see if she could not be persuaded.

A talk that I have titled Guns-Just the Facts, or Guns: A Policy-Free Discussion, illustrates another way that I have tried to encourage people to put aside their cultural biases and think about their willingness to be open to empirical evidence." In the lecture's introduction, I

tural orientations strongly affect individual attitudes on gun control," but that "numerous studies have found that neither actual crime rates [nor] perceived crime rates ... correlate[] with public opinion toward gun control").

${ }^{2}$ David B. Mustard, Guns-Just the Facts (umpublished lecture notes, on file with author). 
state that during my presentation I will discuss issues about which scholars broadly agree on the answers, and that I will not explicitly discuss any laws or policy proposals. I then ask how many audience members think that they have firmly held beliefs about gun policy. My interest is not in their particular viewpoints, but rather in how intensely they hold those viewpoints. Typically about $90 \%$ of the audience indicate that they have very strong beliefs about gun laws. I proceed to ask how many think that if they believe something strongly they at least should have some basic understanding of the underlying data. Virtually everyone raises her hand in response. I then distribute a questionnaire. Consider the following examples from among the series of questions:

How many accidental deaths as a result of frearms are there per year in the United States?

How many accidental deaths of children under five as a result of firearms are there per year in the United States?

How has the accidental dealh rate (deaths per population) as a result of firearms changed since 1970 ? (i.e., increased or decreased by $\mathrm{X}$ percent)

How many times per year are guns used to commil crimes in the United States?

How many times per year are guns used for self-defense in the United States?

What is the ratio of crimes to self-defense uses?

Even when using a charitable grading policy that grants credit to any answer within about $200 \%$, rarely does anyone answer more than about one quarter of the questions correctly-regardless of where they stand on the gun issue. This experiment suggests that even when individuals are strongly committed to a certain belief and agree that it is important for ardently held convictions to be buttressed by evidence, most people have little understanding of the evidence necessary to develop an informed view of the costs and benefits of gun control.

In my presentation, I conclude by generalizing this point and stating that if a person passionately believes something, be it about abortion, the environment, social policy, or firearms, shs-needs to carefully consider the evidence in forming her convictions. Cultural worlviews that close one's mind to new sources of evidence certainly affect views on gun control. In response to such views, it is especially important 
that educators develop pedagogical methods to encourage people to recognize their own cultural biases and lack of receptivity to data.

\section{DO DATA REALLY MATTER?}

Kahan and Braman contend that because the role of culture in determining attitudes toward guns is so strong, "empirical analyses of the effect of gun control on violent crime are unlikely to have much impact." Although I agree with Kahan and Braman's contention that cultural beliefs are important, I strongly disagree with their conclusion that data neither elucidate issues nor persuade people. Kahan and Braman's use of statistical analyses to show that statistical analyses do not help explain peoples' beliefs about firearms is clearly ironic.

Kahan and Braman overstate the role of cultural factors to the exclusion of other factors. For example, their chosen measures of culture (hierarchy-egalitarianism and individualism-solidarism) explain only between $1.5 \%$ and $7 \%$ of peoples' attitudes on firearms (based on the difference in their reported $R^{2}$ 's in the two sets of regressions). Although statistically significant, these variables account for relatively few of the variations in individuals' beliefs about firearms.

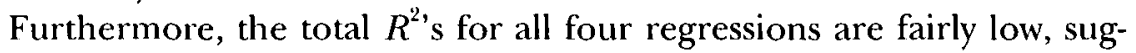
gesting that other factors may also be important for explaining peoples' viewpoints on firearms. I believe data to be one of these other factors.

Although some people may be unwilling to consider data in determining their beliefs, many peoples' viewpoints have undoubtedly been influenced by data. For instance, data have compelled me to significantly change my viewpoints on gun-related issues. When I started my research on guns in 1995, I passionately disliked firearms and fully accepted the conventional wisdom that increasing the gunownership rate would necessarily raise violent crime and accidental deaths. My views on this subject were formed primarily by media accounts of firearms, which unknowingly to me systematically emphasized the costs of firearms while virtually ignoring their benefits." I thought it obvious that passing laws that permitted law-abiding citizens to carry concealed weapons would create many problems. It is now

Kahan \& Braman, supra note 1, at 1292.

Id. at 1306 tbl.1.

"John R. lot"t, JR., The Bias Against Guns: Why Almost Everything YOU've HEARD ABOUT GUN CONTROL IS WRONG 23-48 (2003) (discussing how the media focuses on the negatives of guns). 
over six years since I became convinced otherwise and concluded that shall-issue laws-laws that require permits to be granted unless the applicant has a criminal record or a history of significant mental illness-reduce violent crime and have no impact on accidental deaths." My transformation is not unique; other scholars, such as Gary Kleck, have significantly changed their views about firearms as they learned more about the evidence.

When I began my research on guns in 1976 , like most academics, I was a believer in the "anti-gun" thesis, i.e. the idea th [at] gun availability has a net positive effect on the frequency and/or seriousness of violent acts. It seemed then like self-evident common sense which hardly needed to be empirically tested. However, as a modest body of reliable evidence (and an enormous body of not-so-reliable evidence) accumulated, many of the most able specialists in this area shifted from the "anti-gun" position to a more skeptical stance, in which it was negatively argued that the best available evidence does not convincingly or consistently support the antigun position. This is not the same as saying we know the anti-gun position to be wrong, but rather that there is no strong case for it being correct. The most prominent representatives of the skeptic position would be James Wright and Peter Rossi, authors of the best scholarly review of the literature.

... [Subsequent research] has caused me to move beyond even the skeptic position. I now believe that the best currently available evidence, imperfect though it is (and must always be), indicates that general gun availability has no measurable net positive effect on rates of homicide, suicide, robbery, assault, rape, or burglary in the [United States].

One of the most startling conclusions leading to my transformation was that concealed-weapons permit holders are extremely law abiding. Rarely do they use their guns for inappropriate purposes. ${ }^{8}$ I was most surprised that evidence from many different states and time periods overwhelmingly rejects the claim that concealed-carry laws will

'See John R. Lott, Jr. \& David B. Mustard, Crime, Deterrence, and Right-to-Carry Concealed Handguns, 26 J. LEGAL STUD. 1, 64 (1997) ("Allowing citizens without criminal records or histories of significant mental illness to carry concealed handguns deters violent crimes and appears to produce an extremely small and statistically insignificant change in accidental deaths.").

Gary Kleck, Submission to the National Academy of Sciences/National Research Council Panel on the Understanding and Prevention of Violence: Comments on Philip Cook, The Technology of Personal Violence (Apr. 3, 1990) (on file with author).

See JOHN R. L.OTT, JR., MORE Guns, LESS CRIme $219-22$ (2d ed. 2000) (providing studies that show concealed-handgun permit holders do not pose a risk to others); see also Lott \& Mustard, supra note 6 , at 3 (noting that " 221,443 licenses were issued between October 1, 1987, and April 30, 1994, but only 18 crimes involving firearms were committed by those with licenses"). 
usher in a new era of the "wild west." For example, in Multnomah County, Oregon, only 1 of 11,140 permit holders illegally used a firearm against another person during a four-year period-an annual rate of only 0.2 incidents for every 10,000 holders." The annual rate in Florida over a seven-year period was even lower: 18 crimes involving firearms were committed by gun owners with licenses, out of 221,443 total licenses, producing an annual rate of 0.1 incidents for every 10,000 holders. ${ }^{10}$

Many students, academics, and general citizens have told me how the growing amount and quality of empirical evidence has encouraged them to change their minds on this issue. Some of the most startling testimony along these lines is from law enforcement officers who had vehemently opposed shall-issue laws and now acknowledge that license holders are extremely law abiding and pose little threat." Glenn White, President of the Dallas Police Association, twice lobbied against the Texas proposed right-to-carry law, but after it finally passed he remarked, "Iim a convert." 12 The president and the executive director of the Florida Chiefs of Police and the head of the Florida Sheriff's Association made extensive efforts to document problems arising from their state's shall-issue law. However, they were surprised by the virtual absence of problems." Speaking on behalf of the Kentucky Chiefs of Police Association, Lt. Col. Bill Dorsey stated, "'We haven't seen any cases where a (concealed-carry) permit holder has committed an offense with a firearm."'14 Many academics and policymakers, including some of the above police officers, believed that concealed-carry holders would jeopardize society and actively tried to document that danger. However, in the absence of evidence, and in spite of their best efforts, they were compelled to change their minds. They now believe that law-abiding citizens who have no mental health

Lott \& Mustard, supra note 6 , at 3 n.9.

10 Id. at 3 .

"Se, David B. Mustard, The Impact of Gun Latus on Police Deaths, 44 J.L. \& ECON. 635,638 (2001) (documenting examples of such testimony).

${ }^{12}$ Scott Parks, Charges Against Texans with Gun Permits Rise: Backers, Foes of Comcealed-Weapon Law Split on Meaning of Data, DALLAS MORNING NEwS, Dec. 23, 1997, at Al.

13 Steve Patterson, Concealed-Weapons Law Opponents Still Searching for Ammunition, FloRIDA TIMES-UNION, May 9, 1988, at Al (reporting that opponents of Florida's concealed-weapons law were still looking for detrimental effects directly associated with it).

${ }^{14}$ Terry Flynn, Gun-Toting Kentuckians Hold Their Fire, CINCINNA'T ENQUIRER, June 16, 1997, at A1. Kentucky State Police Trooper Jan Wuchner is also quoted as saying that he has "'heard nothing around the state related to crime with a gun committed by permit holders. There has been nothing like that that I've been informed of." Id. 
histories, who pay fees and give authorities personal information, rarely use their weapons for inappropriate purposes.

A second criticism of Kahan and Braman is that although they correctly highlight some disagreements in the empirical literature, they omit to mention the consensus that is building about the estimates of the impact of the laws-that these laws certainly do not increase crime and likely lower violent crime slightly. The data have already significantly altered the debate. Prior to the recent explosion of gun research, many, including me, presumed that shall-issue laws would increase crime. However, even those who Kahan and Braman cite as being most critical of the Lott-Mustard findings provide little, if any, strong evidence that shall-issue laws increase crime. For example, Mark Duggan reported thirty regressions of the impact of right-tocarry laws on violent crime. ${ }^{15}$ Only one of the thirty coefficient estimates is positive and statistically significant (robbery in one specification). ${ }^{16}$ In contrast, fourteen of the thirty coefficient estimates are negative and statistically significant, and most of the rest are negative and statistically insignificant. ${ }^{17}$ Consequently, even this article that has been cited for calling into question the original Lott-Mustard results contains more evidence that these laws actually reduced rather than increased crime. Similarly, Black and Nagin obtain a positive and significant coefficient in one specification for assaults, but only while using the problematic quadratic estimation procedure. ${ }^{18}$ However, this same table reports thirteen negative and statistically significant coefficient estimates, and the remaining estimates are disproportionately negative and statistically insignificant."

These findings are particularly notable in the broader gun literature because right-to-carry laws are the first type of gun law to consistently produce an empirically verifiable reduction in criminal activity. The empirical work in refereed scholarly journals presents a much stronger case for the efficacy of shall-issue laws in reducing crime than

\footnotetext{
(2001).

${ }^{16} I d$.

${ }^{17}$ Id. Although only twelve are designated as statistically significant in the table, rape and assault in specification (2) are also statistically significant given the reported estimates of the coefficients and standard errors.

${ }^{18}$ Dan A. Black \& Daniel S. Nagin, Do Right-1o-Cany Latus Deter Violent Crime?, 27 J. LEGAL STUD. 209, 218 (1998).

1:1 Id.
}

${ }_{15}^{15}$ Mark Duggan, More Cuns, More Crime, 109 J. POL. ECON. 1086, 1110 tbl.12 
any other gun control law. ${ }^{20}$ From a public policy perspective, if one believes there is insufficient evidence to endorse concealed-carry laws, then to be logically consistent one must also oppose the implementation of waiting periods, safe-storage laws, and other gun laws even more adamantly.

\section{CONCLUSION}

As Kahan and Braman correctly contend, some people hold passionate beliefs about guns, are largely influenced by cultural worldviews, and are unwilling to be persuaded by the data. However, cultural values, as Kahan and Braman define them, explain only about $5 \%$ of peoples' beliefs about firearms. Just because some people may not be persuaded does not mean that nobody is persuaded by data or that we should stop estimating the impacts of gun laws. Many academics, policymakers, and citizens have changed their minds about guns when presented with the evidence. Furthermore, the academic literature, although unable to point to exact estimates of the impacts of gun laws, has placed bounds on their impacts. Therefore, making progress on the firearms debate will require renewed attention to high quality empirical research combined with the development of pedagogical and communication methods that help people realize the implications of their unwillingness to consider evidence.

20 For an examination of the impact of other gun control laws on crime, see LOTT, supra note 8 , at $197-202$. 